\title{
Arterial oxygen saturation during upper gastrointestinal endoscopy: the effects of a midazolam/pethidine combination
}

\author{
A W Murray, C G Morran, G N C Kenny, J R Anderson
}

\begin{abstract}
This study was performed to assess the severity and duration of hypoxia during and after prolonged upper gastrointestinal endoscopy. Twenty patients were studied using a non-invasive pulse oximeter. Significant reductions in oxygen saturation were noted during endoscopy and remained below the preexamination level during the one hour period after the examination. This study indicates that pulse oximetry is a useful monitor for detection of hypoxia during and after endoscopy.
\end{abstract}

Flexible fibreoptic endoscopy of the upper gastrointestinal tract is frequently performed and has a low morbidity and mortality. Hypoxic episodes have been noted, however, in association with endoscopy and electrocardiographical changes associated with the episodes have been reported especially in patients suffering from ischaemic heart disease. ${ }^{1-7}$

More complex and prolonged procedures such as endoscopic retrograde cholangiopancreatography (ERCP) with or without sphincterotomy, and laser therapy to oesophageal and gastric lesions are carried out on increasingly elderly patients who are deemed poor risks for general anaesthetic. As these examinations cause the patient much greater discomfort than diagnostic endoscopy, larger doses of sedative and analgesic drugs may be administered.

Mild degrees of hypoxia can be tolerated in young fit patients without obvious sequelae. In the elderly, and in those patients with preexisting cardiovascular or cerebrovascular disease, a reduction in oxygen supply is likely to exacerbate symptoms. If hypoxaemia is severe or protracted, cardiac arrhythmias and ischaemic changes may progress to myocardial infarction or cardiac arrest. Borderline ischaemic regions of brain are at high risk of infarction during hypoxic episodes. Reversible damage to the brain caused by hypoxia may become manifest after endoscopy when recovery from sedation may appear to be greatly prolonged.

Ambient lighting is often reduced during endoscopy to improve the quality of observation by the operator and detection of cyanosis in these circumstances becomes increasingly difficult. In addition, endoscopy is frequently performed with only one member of medical staff present. As the operator's attention is concentrated on the procedure, deterioration in the patient's condition may only be recognised when a critical event occurs.

The present study was designed to examine the changes in arterial oxyhaemoglobin saturation during, and up to one hour following prolonged endoscopic procedures.

\section{Methods}

PATIENTS

Written informed consent for the study was obtained from 20 patients. Demographic data are shown in Table I. Underlying medical and surgical diseases and the procedures undertaken are detailed in Tables II and III.

Arterial oxyhaemoglobin saturation $\left(\mathrm{SaO}_{2}\right)$ was monitored continuously using an Ohmeda Biox 3700 pulse oximeter. Output from the pulse oximeter was connected to an Atari 1040 ST computer via an analogue to digital converter and the results saved to magnetic disk at one minute intervals. The computer program was designed to reduce the time period between storage to 15 seconds if the oxygen saturation decreased $5 \%$ or more below the baseline observation measured before the administration of any sedative drugs. Measurements continued for the duration of the examination and for one hour into the recovery phase.

Lignocaine was applied to the patients'

TABLE I Demographic data

\begin{tabular}{lll}
\hline & Age (yr) & Weight $(\mathrm{kg})$ \\
\hline Mean & $62 \cdot 45$ & $64 \cdot 55$ \\
Range & $26-85$ & $32-106$ \\
(SEM) & $3 \cdot 35$ & $4 \cdot 43$ \\
& Male & Female \\
Sex & 14 & 6 \\
\hline
\end{tabular}

TABLE II Pre-existing disease in 20 patients undergoing endoscopy

\begin{tabular}{ll}
\hline Condition & $n$ \\
\hline Ischaemic heart disease & 5 \\
Cerebrovascular disease & 3 \\
Valvular heart disease & 1 \\
Hepatic or pancreatic disease & 4 \\
Respiratory disease & 4 \\
\hline
\end{tabular}

TABLE III Endoscopic procedures

\begin{tabular}{ll}
\hline Procedure & $n$ \\
\hline $\begin{array}{l}\text { Endoscopic retrograde } \\
\text { cholangiopancreatography }\end{array}$ & 9 \\
Endoscopy with laser therapy & 7 \\
Upper GI endoscopy & 4 \\
Duration of examination & time $($ min $)$ \\
Mean & $20 \cdot 7$ \\
(SEM) & $2 \cdot 47$ \\
Range & $4-43$ \\
\hline
\end{tabular}


pharynx using 10 doses of $10 \mathrm{mg}$ from a metered spray. Sedative and analgesic drugs were administered intravenously into a fast running infusion by the operator. In accordance with the normal practice for these procedures in our unit, patients were given intravenous pethidine $50 \mathrm{mg}$ if they were aged under 70 years, and pethidine $25 \mathrm{mg}$ if they were older. The sedation was then completed with midazolam, titrated in $2.5 \mathrm{mg}$ increments until the patients' speech became slurred. The mean dose of midazolam was $7 \cdot 77$ $\mathrm{mg}$ (SEM 0.59) and the individual doses ranged from $2.5 \mathrm{mg}$ to $15 \mathrm{mg}$. When the operator was satisfied with the level of sedation, the endoscope was introduced.

All patients were examined in the left lateral position and breathed room air. Arterial saturation was recorded:

\section{During the procedure}

(i) At baseline, before administration of sedative drugs; (ii) at the maximum reduction of saturation during endoscopy; (iii) at the end of endoscopy as the endoscope was withdrawn.

\section{During recovery}

(i) At the beginning of the recovery phase, after transfer to the recovery area; (ii) at the point of maximum desaturation during recovery; (iii) at one hour from the end of endoscopy.

The time period during which oxygen saturation dropped below baseline, and time spent $5 \%$ or more below baseline were noted.

\section{Results}

\section{DURING ENDOSCOPY}

Mean duration of the endoscopy was $20 \cdot 7$ minutes and ranged from four to 43 minutes. The mean baseline saturation measured was below the lower limit for a normal population. This probably reflects the poor cardiorespiratory state of these patients. After administration of sedatives and introduction of the endoscope,

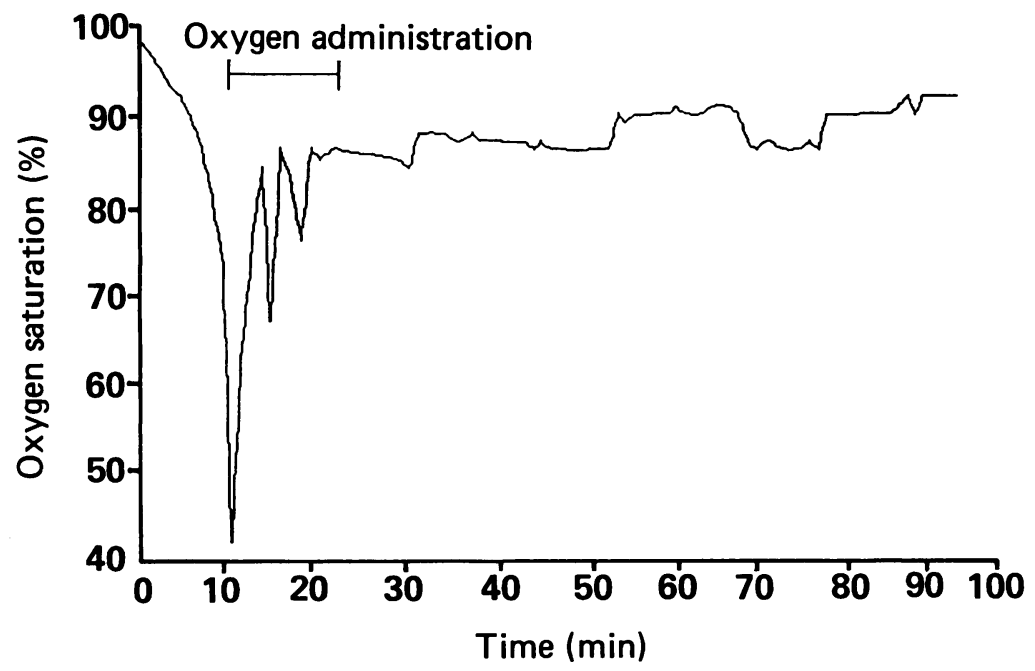

Figure: Oxygen saturations for one patient. This patient had a short respiratory arrest requiring manual ventilation for approximately three minutes. Oxygen was then administered by nasal cannulae for the remainder of the examination at a rate of $2 \mathrm{l} / \mathrm{min} . \mathrm{SaO}_{2}$ of $42 \%$ is approximately equivalent to an arterial $\mathrm{PO}_{2}$ of $20 \mathrm{mmHg}$.
TABLE IV $\mathrm{SaO}_{2}$ at measurement points during the study

\begin{tabular}{lcl}
\hline Event & Saturation (Mean) & (SEM) \\
\hline (a) During endoscopy & & \\
Baseline & 94.4 & 2.54 \\
Minimum saturation & $82.9^{\star} \dagger$ & 12.48 \\
End of examination & $91.6^{\star}$ & 3.64 \\
${ }^{\star} \mathrm{p}<0.01$ compared with baseline & \\
$t \mathrm{p}<0.01$ compared with end of procedure & \\
& & \\
(b) During recovery & \\
Start of recovery & $91.9^{\star}$ & 3.28 \\
Minimum saturation & $90 \cdot 1^{\star}$ & 3.58 \\
End of recovery & 93.9 & 2.45 \\
^ $\mathrm{p}<0.05$ compared with end of recovery (Student's paired $t$ test).
\end{tabular}

reductions in oxyhaemoglobin saturation were noted in all patients (Table IVa). Four patients developed $\mathrm{SaO}_{2}$ of $80 \%$ or below. Of these four patients, two became apnoeic and required ventilatory support for a short time. Supplementary oxygen was given through nasal cannulae until $\mathrm{SaO}_{2}$ was above $90 \%$.

There were significant differences in saturation between baseline and the lowest value recorded during endoscopy $(p<0.01)$ and also between the baseline and the value measured at the end of endoscopy $(\mathrm{p}<0.05)$. The difference between the end of the examination and the maximum desaturation was also significant $(p<0 \cdot 01)$.

\section{DURING RECOVERY}

Arterial oxygen saturation improved significantly from the beginning to the end of the recovery period $\left(p<0.05\right.$, Table IVb). The lowest $\mathrm{SaO}_{2}$ during the recovery phase was greater than the lowest $\mathrm{SaO}_{2}$ recorded during endoscopy, but was significantly below the baseline level and the value obtained at the end of recovery. The maximum desaturation recorded during the recovery period was not significantly different from the start of recovery. There was no significant difference between saturations at baseline and the end of one hour recovery: however, at this point, 11 patients had still not recovered to their baseline levels.

The mean duration spent with oxyhaemoglobin saturation below baseline was 73.5 minutes (range 6-103 $\mathrm{min}$ ) and time spent $5 \%$ or more below baseline was $9 \cdot 1$ minutes (range 1-33 $\min$ ).

\section{Discussion}

Pulse oximetry has shown that desaturation can occur rapidly and can be profound (Figure). The present study has confirmed that hypoxaemia is precipitated by administration of sedative drugs and insertion of an endoscope into the upper gastrointestinal tract. Four patients developed arterial saturations below $80 \%$ which is approximately equivalent to an arterial $\mathrm{PO}_{2}$ of $40 \mathrm{mmHg}(5.32 \mathrm{kPa})$. The average minimum $\mathrm{SaO}_{2}$ during endoscopy was $82 \cdot 9 \%$ which corresponds to an arterial $\mathrm{PO}_{2}$ of approximately $46 \mathrm{mmHg}(6 \cdot 12 \mathrm{kPa})$. The maximum drop in any individual patient was to $42 \%$. We have also shown the persistence of hypoxaemia beyond the end of the procedure. The mean minimum $\mathrm{SaO}_{2}$ during the recovery phase was $90 \cdot 1 \%$ which corresponds to a $\mathrm{PO}_{2}$ of $65 \mathrm{mmHg}(8.64 \mathrm{kPa})$, 
but one patient had a minimum saturation of $84 \%$ or $56 \mathrm{mmHg}(7 \cdot 45 \mathrm{kPa})$. Some patients remained below their baseline measurements more than one hour later. The problem of hypoxia therefore extends beyond the period of endoscopic examination and vigilance must be maintained during this time.

Clinical observation for physical signs of hypoxaemia are subjective, non-specific and unreliable. ${ }^{8}$ Observation of cyanosis and respiratory pattern can be made more difficult when ambient lighting is reduced to facilitate endoscopy.

Many previous studies of oxygenation during upper gastrointestinal endoscopy have relied on intermittent sampling of arterial blood. ${ }^{1-35}$ Analysis may take several minutes, require the services of a technician and important information may be missed in the periods between sampling. It is also impractical to consider arterial sampling for routine monitoring of patients undergoing endoscopy. Ear oximetry has also been used effectively to measure oxygen saturation, however, these instruments tend to be large and expensive. Pulse oximetry has been shown to be reliable and to provide an accurate measurement of haemoglobin oxygen saturation in critically ill patients over a wide range of arterial saturations. ${ }^{9}$

Sedation is used to facilitate endoscopy and render it more acceptable to the patient. Benzodiazepines are used commonly, sometimes in combination with an analgesic to achieve a state of tranquillity, amnesia, and cooperation. Zsigmond and his coworkers showed that intravenous diazepam given to healthy volunteers caused minimal changes in arterial $\mathrm{PO}_{2},{ }^{10}$ but the hypoxaemia became significant when the benzodiazepine was combined with an opioid analgesic. This effect was noted to be more marked when the studies were performed in groups of patients suffering from chronic obstructive pulmonary disease. ${ }^{11}$

Intravenous midazolam has replaced diazepam in many units because of the potential advantages of shorter half life with rapid recovery, and lack of venous irritation and phlebitis. It has been shown that midazolam produces a slightly greater, but not statistically different, reduction in oxygen saturation than an equipotent dose of diazepam. ${ }^{12}$ A recent study has confirmed that marked drops in oxygen saturation occur after the administration of midazolam and that these appeared to be related to reductions in respiratory rate and respiratory excursion. ${ }^{13}$ Further reductions in saturations were seen after the introduction of the endoscope which provoked gagging and coughing. The lowest mean oxygen saturation was $89 \%$ which is much higher when compared with the $82.9 \%$ in the present study. This difference between the studies is probably caused by the effect of pethidine.

Electrocardiographical changes have been observed concurrently with hypoxaemic episodes during endoscopic examination. They have been mainly premature ventricular beats and, in one case, slowing of ventricular response in a patient with atrial fibrillation.' These changes all reverted to pre-examination levels within one hour of the end of endoscopy.
Introduction of an endoscope has been shown to induce similar significant reductions in oxygen tension whether benzodiazepines are given or withheld. ${ }^{23}$ It was thought that partial obstruction of respiration after introduction of an endoscope, aspiration of gastric contents, ventilation perfusion inequality secondary to changes in autonomic tone or a combination of several of these factors contributed to this effect. A study by Lavies has shown that a greater reduction in oxygen saturation can be caused by an inexperienced endoscopist. ${ }^{4}$

More marked reductions in saturation were noted during endoscopy when the sedative action of the benzodiazepine was augmented with pethidine. Rozen and his colleagues have shown that the degree of hypoxaemia can be reduced with the use of short acting opioid drugs or the use of a narrow diameter paediatric endoscope. ${ }^{5}$ Furthermore, the combination of short acting opioid and narrow diameter endoscope was found to minimise the drop of arterial oxygen saturation during the examination.

Almost all previous studies of oxygenation during upper gastrointestinal endoscopy have shown that hypoxia occurs. A recent study has shown that hypoxia can be minimised by the administration of nasal oxygen during the procedure and recommend that supplementary oxygen be given to all elderly patients and particularly those with cardiovascular disease. ${ }^{14}$ Because non-invasive monitoring of oxygenation is now readily available and relatively inexpensive, it would appear mandatory to apply this technique when high risk patients are subjected to profound sedation and prolonged endoscopic examination. In the absence of pulse oximetry, we would vigorously endorse the view of Bell and his coworkers in recommending the administration of oxygen to these patients. ${ }^{14}$

Arterial saturation does not always continue to improve immediately after endoscopy and may decrease further when the patient is returned to the recovery area. It is important, therefore, to continue monitoring of oxygenation and oxygen therapy until the patient has recovered adequately.

We would like to thank the nursing staff of the endoscopy suite and recovery area of the Royal Infirmary for their cooperation and help.

1 Rostykus PS, McDonald GB, Albert RK. Upper intestinal endoscopy induces hypoxaemia in patients with obstructive pulmonary disease. Gastroenterology 1980; 78: 488-91.

2 Whorwell PJ, Smith CL, Foster KJ. Arterial blood gas tensions during upper gastro-intestinal endoscopy. Gut 1976; 17: 797-800

3 Pecora AA, Chiesa JC, Alloy AM, Santoro J, Lazarus B. The effect of upper gastro-intestinal endoscopy on arterial oxygen tension in smokers and non-smokers with and without premedication. Gastrointest Endosc. 1984; 30: 284 8.

4 Lavies NG, Creasy T, Harris K, Hanning CD. Arterial oxygen saturation during upper gastrointestinal endoscopy: influence of sedation and operator experience. Am $\mathcal{J}$ Gastroenterol 1988; 83: 618-22.

5 Rozen P, Fireman Z, Gilat T. Arterial oxygen tension changes in elderly patients undergoing upper gastro-intestinal endoscopy II. Influence of the narcotic premedication and endoscope diameter. Scand $\mathcal{F}$ Gastroenterol 1981; 16: 299endosco 303.

6 Rozen P, Fireman Z, Gilat T. The causes of hypoxaemia in elderly patients during endoscopy. Gastrointest Endosc 1982; 28: 243-6.

7 Jones G. Oxygen saturation during upper gastrointestinal endoscopy. Brf Anaesth 1986; 58: 807. 
8 Neil SG, Lam AM, Turnbull KW, Tremper KK. Monitoring of oxygen. Can f Anaesth 1987; 34: 56-63.

9 Mihm FG, Halperin BD. Noninvasive detection of profound arterial desaturations using a pulse oximeter device. Ancesthesiology 1985;62:85-7.

10 Zsigmond EK, Flynn K, Martinez OA. Diazepam and meperidine on arterial blood gases in healthy volunteers. meperidine on arterial blood gases in healthy volunteers.
7 Clin Pharmacol $1974 ; 14: 377-81$.

11 Zsigmond EK, Shively JG, Flynn K. Diazepam and meperidine on arterial blood gases in patients with chronic
obstructive pulmonary disease. $\mathcal{F}$ Clin Pharmacol 1975; 15: 464-9.
12 Bell GD, Morden A, Coady T, Lee J, Logan RFA. A comparison of diazepam and midazolam as endoscopy premedication assessing changes in ventilation and oxygen saturation. Br F Clin Pharmacol 1988; 26: 595-600.

13 Bell GD, Reeve PA, Moshiri M, et al. Intravenous midazolam: a study of the degree of oxygen desaturation occurring during upper gastrointestinal endoscopy. $\mathrm{Br} \mathcal{F}$ Clin Pharmacol 1987; 23: 703-8.

14 Bell GD, Bown S, Morden A, Coady T, Logan RFA. Prevention of hypoxaemia during upper-gastrointestinal endoscopy by means of oxygen via nasal cannulae. Lancet 1987; i: $1022-4$. 